\title{
Problem-Based Learning in Child and Adolescent Psychiatry: A Perspective from Japan
}

Junko Iwatsuki (D) ${ }^{1,2}$

Takeshi Kondo $\mathbb{D D}^{3}$

Noriyuki Takahashi $\mathbb{D D}^{3-5}$

Hideki Takami ${ }^{3}$ Hiroshi Nishigori ${ }^{6}$

Itzel Bustos-Villalobos ${ }^{7}$

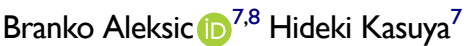

Nobutaro Ban ${ }^{9}$ Tetsuya Yagi ${ }^{10}$

Norbert Skokauskas ${ }^{11,12}$

'International Collaboration Planning

Center, Institute of International

Education and Exchange, Nagoya

University, Nagoya, Japan; ${ }^{2}$ Present

Affiliation is Office for International

Education and Exchange, Faculty and

Graduate School of Economics, Kobe

University, Kobe, Japan; ${ }^{3}$ Center for

Postgraduate Clinical Training and Career

Development, Nagoya University

Hospital, Nagoya, Japan; ${ }^{4}$ Department of

General Medicine/Family \& Community

Medicine, Nagoya University Graduate

School of Medicine, Nagoya, Japan;

${ }^{5}$ Department of Education for Community-

Oriented Medicine, Nagoya University

Graduate School of Medicine, Nagoya,

Japan; ${ }^{6}$ Center for Medical Education,

Nagoya University Graduate School of

Medicine, Nagoya, Japan; ${ }^{7}$ Department of

International Medical Education, Nagoya

University Graduate School of Medicine,

Nagoya, Japan; ${ }^{8}$ Department of Psychiatry,

Nagoya University Graduate School of

Medicine, Nagoya, Japan; ' $M$ Medical Education

Center, Aichi Medical University School of

Medicine, Nagakute, Japan; ${ }^{10}$ Department of

Infectious Diseases, Nagoya University

Graduate School of Medicine, Nagoya,

Japan; " 'Regional Centre for Child and Youth

Mental Health and Child Welfare,

Department of Mental Health, Norwegian

University of Science and Technology,

Trondheim, Norway; ${ }^{2}$ Department of Child

and Adolescent Psychiatry, St. Olavs

University Hospital, Trondheim, Norway

Correspondence: Branko Aleksic

Nagoya University Graduate School of

Medicine, 65 Tsurumai-Cho, Showa-ku,

Nagoya, 466-8550, Japan

Tel +8I 527442282

Fax +8I 527442293

Email branko@med.nagoya-u.ac.jp
Purpose: Japanese higher education institutions have long been striving for the globalization of medical education. Nagoya University (NU) adopted PBL as a means of enhancing intercultural awareness in globalizing medical education by working with the Norwegian University of Science and Technology (NTNU), Faculty of Medicine and Health Science, under the Trondheim NTNU-Nagoya (TroNa) partnership for mobility and internationalization of child and mental health studies. This study aims to assess students' attitudes towards PBL and to suggest future developments in this form of education by introducing common PBL scenarios experienced at NTNU and NU.

Methods: Two 90-minute PBL sessions were conducted at NU. Ten groups of medical students were formed, each consisting of up to 10 students, and students were asked to fill in a questionnaire developed to assess their understanding of, attitudes to and satisfaction with the classes. We investigated three different groups of questions on: NU medical students' general impressions of PBL; their impressions of PBL in child and adolescent psychiatry (CAP); and their impressions of PBL in specific case scenarios. Correlations between each of the questions from the three groups were evaluated using multivariate analysis.

Results: Overall, a majority of the NU medical students were satisfied with PBL, while a small number preferred traditional lecture-style learning $(5 \%)$. More than half of the students agreed that PBL increased their understanding and interest in CAP (53\%), although some male students felt that the amount of time spent was insufficient $(20.3 \%)$. Correlations were seen for students who thought that PBL enhanced their understanding of and interest in CAP. Regarding case scenarios, most students $(82.5 \%)$ agreed that PBL helped them to develop clinical problem-solving skills.

Conclusion: The study found an overall positive attitude towards PBL, PBL in CAP and the specific PBL case scenario presented.

Keywords: problem-based learning, child psychiatry, children and mental health, English medical education, internationalization

\section{Introduction}

Japan, the world's third largest economy, is dealing with extreme versions of the demographic challenges that face many developed countries. The rapid growth of an aging population is putting pressure on social and health services. A declining birth rate means that there are fewer young people to provide care for older people. ${ }^{1}$ There is also growing pressure on the so-called "sandwich generation," aged 35-54, who care for both their growing children and their aging parents. Parental stress, school pressures and social media all have roles in children's mental well-being. ${ }^{2}$ So, while the absolute number of children is shrinking in Japan, there is no doubt 
that many health professionals, and especially medical doctors, will be providing support for children and their families with mental health needs in the near future. ${ }^{3}$ Considering that stigma related to mental health disorders is lessening in Japan, ${ }^{4}$ the need for child and mental health services will most likely increase, despite the demographic changes in the country. In the provision of mental health services, well-trained human resources play a crucial role.

Hence, medical students will need to learn how to deal with common mental disorders in children and how to help those children and their parents. Therefore, having a good understanding of child mental health disorders and their management will become indispensable for all medical students, regardless of their future specialization. ${ }^{5}$

In the 1960s, the Faculty of Medicine at McMaster University, Ontario embarked on a pedagogical experiment known as problem-based learning (PBL). PBL was one of the most innovative instructional methods conceived in the history of education and was initially designed to respond to criticism that traditional teaching and learning methods failed to prepare medical students for solving problems in clinical settings. ${ }^{5-7} \mathrm{PBL}$ is an effective teaching method where students develop flexible knowledge, problemsolving and collaboration skills through their experiences. ${ }^{8}$

In Japan, PBL was first introduced in 1990 at Tokyo Women's Medical University, following a global trend of curriculum reform. However, the PBL curriculum was relatively slow to spread to other Japanese medical schools, ${ }^{9,10}$ and it was only in 2003 that Nagoya University (NU), a distinguished Japanese higher education institution, ${ }^{11}$ adopted the PBL curriculum in clinical and social medicine disciplines.

At NU, PBL was introduced to medical students in their second, third and fourth years, but due to the shortage of medical PBL experts, it is currently used to teach fourth-year undergraduate medical students only. The PBL curriculum runs twice a week over a 10-month period, which means that fourth-year medical students devote about one-third of their time to PBL education.

At present, child and adolescent psychiatry (CAP) and other disciplines are taught to fourth-year medical students at NU using three methods: didactic lectures, where the educational approach is a teacher-centered style; practical training seminars, where clinical skills are taught (ie, medical interviewing, physical examinations and other basic clinical skills); and PBL.

The adoption of PBL could be seen as an early attempt to introduce Western teaching methods in Japan.
Like most other universities in Japan, NU has promoted the globalization of education and has nurtured globally minded human resources by accepting medical students from abroad, sending out Japanese students to partner universities and providing medical English courses for Japanese students before their overseas assignments. NU's globalization efforts are supported by a number of policies and programs, including the G30 International Programs, which are full-degree programs taught entirely in English. Through a multi-disciplinary general education curriculum, these programs aim to cultivate ethical leaders who are able to develop innovative solutions through inquiry and analysis and who have strong communication skills, to be productive members of our global society.

PBL for medical students at NU is considered a progressive teaching method and a tool to facilitate the globalization of medical education. Part of PBL is conducted in English and is facilitated by both nonJapanese and Japanese medical educators. Moreover, international collaborative efforts are used to create PBL materials at the university. For example, the medical faculties at NU and the Norwegian University of Science and Technology (NTNU) have established the Trondheim NTNU-Nagoya partnership for the mobility and internationalization of child and mental health studies (the TroNa Partnership), with the aim of enhancing intercultural awareness and understanding in globalizing medical education and strengthening progressive teaching methods such as PBL.

This paper describes joint efforts to build the faculties' capacities in PBL, to adjust, adapt and implement NTNU cases at NU, to assess the implementation process and to suggest future developments in PBL.

\section{Method}

The TroNa Partnership has organized several PBL capacity-building workshops in Japan and Norway. As part of this joint learning process, experts from both countries have worked together to develop joint PBL scenarios as well as a questionnaire to assess the implementation process and students' attitudes towards PBL.

One of the first PBL cases jointly developed focused on a hypothetical 15-year-old girl (Mayumi) brought to child and adolescent mental health services by her parents, with the chief complaints being her careless, defiant and negative behavior, with increased absence from school and deteriorating school performance. 
The objectives of this tutorial were:

-to understand how depression presents in child and adolescent mental health services,

-to learn how and when to initiate antidepressant therapy, including the decision process regarding when the patient should be referred to inpatient hospital care,

-to be aware of other forms of treatment of depression, -to help prevent and treat the recurrence of illness.

All procedures performed in the study involving human participants were in accordance with the ethical standards of the institutional and/or national research committee and with the 1964 Helsinki Declaration and its later amendments or comparable ethical standards. This study was noninterventional (survey), and at the time it was conducted ethical approval by a specialized committee was not required (as confirmed with representatives of the ethical committee at NU). Details of the study were explained to participants beforehand. Signed consent was obtained from all participants.

This case was introduced to fourth-year students at NU medical school in 2019. Each PBL group consisted of 10 students and had one designated group leader (student A) and a note-taker (student B). One PBL tutor was a fulltime member of academic staff working at the school of medicine who was involved in teaching clinical subjects on undergraduate courses. All the PBL groups used the same English-language scenario, and students were asked to choose a language for discussion. Only one group conducted discussions in English, while the remaining nine groups conducted discussions in Japanese.

After two 90-minute PBL sessions, students were asked to fill out a questionnaire that had been developed to assess their understanding of the classes and their attitudes to and satisfaction with the PBL teaching. In total 109 students participated (the survey was offered to 112 students in total, three students did not return the survey). A quantitative approach was utilized in this survey, which consisted of 15 questions using a three-point Likert scale consisting of 1 = agree, 2 = neutral and 3 = disagree.

We used JMP Pro 15 software to calculate the fundamental descriptive statistical indicators for our sample set. The tables in this paper describe the following three different groups of questions: NU medical students' general impressions of PBL; their impressions of $\mathrm{PBL}$ in CAP; and their impressions of PBL in specific case scenarios. We used multivariate analysis to evaluate the correlation between each of the questions in these three groups of questions. We then calculated Pearson's pairwise correlations. Differences were considered significant at $\mathrm{p} \leq 0.05$.

\section{Results}

In total 112 medical students at NU between the ages of 21 and 27 participated in this study. Of these 112 students, two were absent, one student did not submit the questionnaire and 12 students (11\%) did not provide their gender or their age. These students were excluded from the analysis, resulting in a total of 97 students $(n=97)$ whose data were analyzed and presented. The gender and ages of the study sample are described in Table 1.

As described in Table 2, most of the medical students $(82.5 \%)$ agreed that PBL helped them to develop clinical problem-solving skills. More males agreed with this statement than females. More than two-thirds (72.2\%) of the students thought that PBL was a suitable learning method. Similarly, two-thirds $(66 \%)$ of the students said that it encouraged selflearning, while only $5 \%$ disagreed. A majority of students thought that PBL helped them to develop communication skills $(69.1 \%)$ and that PBL was a more effective way of learning than traditional lectures (66\%). Only $5 \%$ of students thought that lectures were a more effective way of learning.

More than half (53.6\%) of the students thought that PBL helped enhance their understanding of CAP, and only $10.3 \%$ disagreed (Table 3). More than half (55.7\%) thought that PBL increased their interest in CAP. More than half (56.5\%) of the female students agreed that learning about CAP through PBL was especially helpful because of its emphasis on teamwork and collaboration. Interestingly, only $41.9 \%$ of the male students agreed with this.

As shown in Table 4, the majority of students (56.7\%), and especially female students (69.6\%), agreed that Mayumi's case was common for a clinical setting in Japan. More than half (57.7\%) thought that the case was well written and easy to understand. However, fewer than half $(42.3 \%)$ thought that the case scenario was interesting with regards to clinical education. On the other hand,

Table I Demographic Characteristics of Participants

\begin{tabular}{|l|l|l|l|l|l|l|l|c|}
\hline & \multicolumn{7}{|c|}{ Age } & \multirow{2}{*}{ Total* } \\
\cline { 2 - 8 } & $\mathbf{2 1}$ & $\mathbf{2 2}$ & $\mathbf{2 3}$ & $\mathbf{2 4}$ & $\mathbf{2 5}$ & $\mathbf{2 6}$ & $\mathbf{2 7}$ & \\
\hline $\begin{array}{l}\text { Female } \\
\text { Male }\end{array}$ & 6 & 9 & 5 & 1 & 2 & 0 & 0 & $23(23.7 \%)$ \\
\hline Total & 21 & 43 & 18 & 1 & 1 & 4 & 2 & $74(76.3 \%)$ \\
\hline
\end{tabular}

Note: $*(n=97$ after disregarding students who did not identify their gender/age). 
Table 2 General Impressions of PBL

\begin{tabular}{|c|c|c|c|c|c|c|c|c|c|}
\hline & \multicolumn{3}{|c|}{ Female (23) } & \multicolumn{3}{|c|}{ Male (74) } & \multicolumn{3}{|c|}{ Total $(97)^{*}$} \\
\hline & Agree & Neutral & Disagree & Agree & Neutral & Disagree & Agree & Neutral & Disagree \\
\hline $\begin{array}{l}\text { I. PBL helps me to } \\
\text { develop skills in solving } \\
\text { clinical problems. }\end{array}$ & $\begin{array}{c}18 \\
(78.3 \%)\end{array}$ & $\begin{array}{c}4 \\
(17.4 \%)\end{array}$ & $\begin{array}{c}\text { I } \\
(4.3 \%)\end{array}$ & $\begin{array}{c}62 \\
(83.8 \%)\end{array}$ & $\begin{array}{c}10 \\
(13.5 \%)\end{array}$ & $\begin{array}{c}2 \\
(2.7 \%)\end{array}$ & $\begin{array}{c}80 \\
(82.5 \%)\end{array}$ & $\begin{array}{c}14 \\
(14.4 \%)\end{array}$ & $\begin{array}{c}3 \\
(3.1 \%)\end{array}$ \\
\hline $\begin{array}{l}\text { 2. PBL is a good way of } \\
\text { learning the content of } \\
\text { the course. }\end{array}$ & $\begin{array}{c}16 \\
(69.6 \%)\end{array}$ & $\begin{array}{c}6 \\
(26.1 \%)\end{array}$ & $\begin{array}{c}\text { I } \\
(4.3 \%)\end{array}$ & $\begin{array}{c}54 \\
(73 \%)\end{array}$ & $\begin{array}{c}16 \\
(21.6 \%)\end{array}$ & $\begin{array}{c}4 \\
(5.4 \%)\end{array}$ & $\begin{array}{c}70 \\
(72.2 \%)\end{array}$ & $\begin{array}{c}22 \\
(22.7 \%)\end{array}$ & $\begin{array}{c}5 \\
(5.1 \%)\end{array}$ \\
\hline $\begin{array}{l}\text { 3. PBL encourages my } \\
\text { self-directed learning. }\end{array}$ & $\begin{array}{c}16 \\
(69.6 \%)\end{array}$ & $\begin{array}{c}7 \\
(30.4 \%)\end{array}$ & $\begin{array}{c}0 \\
(0 \%)\end{array}$ & $\begin{array}{c}48 \\
(64.9 \%)\end{array}$ & $\begin{array}{c}21 \\
(28.4 \%)\end{array}$ & $\begin{array}{c}5 \\
(6.7 \%)\end{array}$ & $\begin{array}{c}64 \\
(66 \%)\end{array}$ & $\begin{array}{c}28 \\
(28.9 \%)\end{array}$ & $\begin{array}{c}5 \\
(5.1 \%)\end{array}$ \\
\hline $\begin{array}{l}\text { 4. PBL helps develop my } \\
\text { communication skills. }\end{array}$ & $\begin{array}{c}14 \\
(60.9 \%)\end{array}$ & $\begin{array}{c}9 \\
(39.1 \%)\end{array}$ & $\begin{array}{c}0 \\
(0 \%)\end{array}$ & $\begin{array}{c}53 \\
(71.6 \%)\end{array}$ & $\begin{array}{c}15 \\
(20.3 \%)\end{array}$ & $\begin{array}{c}6 \\
(8.1 \%)\end{array}$ & $\begin{array}{c}67 \\
(69.1 \%)\end{array}$ & $\begin{array}{c}24 \\
(24.7 \%)\end{array}$ & $\begin{array}{c}6 \\
(6.2 \%)\end{array}$ \\
\hline $\begin{array}{l}\text { 5. I think that PBL is } \\
\text { a more effective way of } \\
\text { learning compared with } \\
\text { traditional lectures. }\end{array}$ & $\begin{array}{c}12 \\
(52.2 \%)\end{array}$ & $\begin{array}{c}10 \\
(43.5 \%)\end{array}$ & $\begin{array}{c}\text { I } \\
(4.3 \%)\end{array}$ & $\begin{array}{c}52 \\
(70.3 \%)\end{array}$ & $\begin{array}{c}18 \\
(24.3 \%)\end{array}$ & $\begin{array}{c}4 \\
(5.4 \%)\end{array}$ & $\begin{array}{c}64 \\
(66 \%)\end{array}$ & $\begin{array}{c}28 \\
(28.9 \%)\end{array}$ & $\begin{array}{c}5 \\
(5.1 \%)\end{array}$ \\
\hline
\end{tabular}

Note: $*(n=97$ after disregarding students who did not identify their gender/age $)$.

Table 3 Questions About PBL and CAP

\begin{tabular}{|c|c|c|c|c|c|c|c|c|c|}
\hline & \multicolumn{3}{|c|}{ Female (23) } & \multicolumn{3}{|c|}{ Male (74) } & \multicolumn{3}{|c|}{ Total (97)* } \\
\hline & Agree & Neutral & Disagree & Agree & Neutral & Disagree & Agree & Neutral & Disagree \\
\hline $\begin{array}{l}\text { 6. PBL enhanced my understanding } \\
\text { about child and adolescent } \\
\text { psychiatry. }\end{array}$ & $\begin{array}{c}13 \\
(56.5 \%)\end{array}$ & $\begin{array}{c}9 \\
(39.1 \%)\end{array}$ & $\begin{array}{c}\text { I } \\
(4.4 \%)\end{array}$ & $\begin{array}{c}39 \\
(52.7 \%)\end{array}$ & $\begin{array}{c}26 \\
(35.1 \%)\end{array}$ & $\begin{array}{c}9 \\
(12.2 \%)\end{array}$ & $\begin{array}{c}52 \\
(53.6 \%)\end{array}$ & $\begin{array}{c}35 \\
(36.1 \%)\end{array}$ & $\begin{array}{c}10 \\
(10.3 \%)\end{array}$ \\
\hline $\begin{array}{l}\text { 7. PBL increased my interest in child } \\
\text { and adolescent psychiatry. }\end{array}$ & $\begin{array}{c}14 \\
(60.9 \%)\end{array}$ & $\begin{array}{c}8 \\
(34.8 \%)\end{array}$ & $\begin{array}{c}1 \\
(4.3 \%)\end{array}$ & $\begin{array}{c}40 \\
(54.0 \%)\end{array}$ & $\begin{array}{c}23 \\
(31.1 \%)\end{array}$ & $\begin{array}{c}11 \\
(14.8 \%)\end{array}$ & $\begin{array}{c}54 \\
(55.7 \%)\end{array}$ & $\begin{array}{c}31 \\
(32 \%)\end{array}$ & $\begin{array}{c}12 \\
(12.3 \%)\end{array}$ \\
\hline $\begin{array}{l}\text { 8. Child and adolescent psychiatry, } \\
\text { because of its emphasis on } \\
\text { teamwork and collaboration, would } \\
\text { be a specialty learned optimally } \\
\text { through PBL. }\end{array}$ & $\begin{array}{c}13 \\
(56.5 \%)\end{array}$ & $\begin{array}{c}9 \\
(39.1 \%)\end{array}$ & $\begin{array}{c}\text { I } \\
(4.4 \%)\end{array}$ & $\begin{array}{c}31 \\
(41.9 \%)\end{array}$ & $\begin{array}{c}34 \\
(45.9 \%)\end{array}$ & $\begin{array}{c}9 \\
(12.2 \%)\end{array}$ & $\begin{array}{c}44 \\
(45.4 \%)\end{array}$ & $\begin{array}{c}43 \\
(44.3 \%)\end{array}$ & $\begin{array}{c}10 \\
(10.3 \%)\end{array}$ \\
\hline $\begin{array}{l}\text { 9. The duration of the PBL sessions } \\
\text { was sufficient for me to learn about } \\
\text { child and adolescent psychiatry. }\end{array}$ & $\begin{array}{c}12 \\
(52.2 \%)\end{array}$ & $\begin{array}{c}9 \\
(39.1 \%)\end{array}$ & $\begin{array}{c}2 \\
(8.7 \%)\end{array}$ & $\begin{array}{c}34 \\
(45.9 \%)\end{array}$ & $\begin{array}{c}25 \\
(33.8 \%)\end{array}$ & $\begin{array}{c}15 \\
(20.3 \%)\end{array}$ & $\begin{array}{c}46 \\
(47.4 \%)\end{array}$ & $\begin{array}{c}34 \\
(35.1 \%)\end{array}$ & $\begin{array}{c}17 \\
(17.5 \%)\end{array}$ \\
\hline $\begin{array}{l}\text { 10. I enjoyed learning about child } \\
\text { and adolescent psychiatry via PBL. }\end{array}$ & $\begin{array}{c}13 \\
(56.52 \%)\end{array}$ & $\begin{array}{c}9 \\
(39.13 \%)\end{array}$ & $\begin{array}{c}1 \\
(4.4 \%)\end{array}$ & $\begin{array}{c}30 \\
(40.5 \%)\end{array}$ & $\begin{array}{c}33 \\
(44.6 \%)\end{array}$ & $\begin{array}{c}11 \\
(14.9 \%)\end{array}$ & $\begin{array}{c}43 \\
(44.3 \%)\end{array}$ & $\begin{array}{c}42 \\
(43.3 \%)\end{array}$ & $\begin{array}{c}12 \\
(12.4 \%)\end{array}$ \\
\hline
\end{tabular}

Note: $*(n=97$ after disregarding students who did not identify their gender/age).

$60.9 \%$ of female and $52.7 \%$ of male students agreed that Mayumi's case had an appropriate level of difficulty/challenges. In addition, $65.2 \%$ of female and $58.1 \%$ of male students agreed that Mayumi's case helped them to understand the importance of a multidisciplinary approach in child and adolescent psychiatry.
Strong correlations were observed in students who thought that PBL enhanced their understanding of CAP and also agreed that it increased their interest in CAP (Table 5) $(\mathrm{R}=0.7443)$. Students who thought that PBL helped develop clinical problem-solving skills also tended to agree that PBL was a good way of learning $(\mathrm{R}=$ 
Table 4 Specific Questions About the Case of “Mayumi” (Adolescent Depression)

\begin{tabular}{|c|c|c|c|c|c|c|c|c|c|}
\hline & \multicolumn{3}{|c|}{ Female (23) } & \multicolumn{3}{|c|}{ Male (74) } & \multicolumn{3}{|c|}{ Total (97)* } \\
\hline & Agree & Neutral & Disagree & Agree & Neutral & Disagree & Agree & Neutral & Disagree \\
\hline $\begin{array}{l}\text { II. I think Mayumi's case } \\
\text { was common for a clinical } \\
\text { setting in Japan. } \\
\text { I2. Mayumi's case was } \\
\text { well written and } \\
\text { understandable. }\end{array}$ & $\begin{array}{c}16 \\
(69.6 \%) \\
12 \\
(52.2 \%)\end{array}$ & $\begin{array}{c}5 \\
(21.7 \%) \\
9 \\
(39.1 \%)\end{array}$ & $\begin{array}{c}2 \\
(8.7 \%) \\
\\
2 \\
(8.7 \%)\end{array}$ & $\begin{array}{c}39 \\
(52.7 \%) \\
\\
44 \\
(59.5 \%)\end{array}$ & $\begin{array}{c}29 \\
(39.2 \%) \\
23 \\
(31.1 \%)\end{array}$ & $\begin{array}{c}6 \\
(8.1 \%) \\
7 \\
(9.4 \%)\end{array}$ & $\begin{array}{c}55 \\
(56.7 \%) \\
\\
56 \\
(57.7 \%)\end{array}$ & $\begin{array}{c}34 \\
(35.1 \%) \\
32 \\
(33 \%)\end{array}$ & $\begin{array}{c}8 \\
(8.2 \%) \\
9 \\
(9.3 \%)\end{array}$ \\
\hline $\begin{array}{l}\text { 13. Mayumi's case has an } \\
\text { interesting clinical trigger. }\end{array}$ & $\begin{array}{c}8 \\
(34.8 \%)\end{array}$ & $\begin{array}{c}13 \\
(56.5 \%)\end{array}$ & $\begin{array}{c}2 \\
(8.7 \%)\end{array}$ & $\begin{array}{c}33 \\
(44.6 \%)\end{array}$ & $\begin{array}{c}34 \\
(45.9 \%)\end{array}$ & $\begin{array}{c}7 \\
(9.5 \%)\end{array}$ & $\begin{array}{c}41 \\
(42.3 \%)\end{array}$ & $\begin{array}{c}47 \\
(48.5 \%)\end{array}$ & $\begin{array}{c}9 \\
(9.2 \%)\end{array}$ \\
\hline $\begin{array}{l}\text { 14. Mayumi's case had an } \\
\text { appropriate level of } \\
\text { difficulty. }\end{array}$ & $\begin{array}{c}14 \\
(60.9 \%)\end{array}$ & $\begin{array}{c}7 \\
(30.4 \%)\end{array}$ & $\begin{array}{c}2 \\
(8.7 \%)\end{array}$ & $\begin{array}{c}39 \\
(52.7 \%)\end{array}$ & $\begin{array}{c}31 \\
(41.9 \%)\end{array}$ & $\begin{array}{c}4 \\
(5.4 \%)\end{array}$ & $\begin{array}{c}53 \\
(54.6 \%)\end{array}$ & $\begin{array}{c}38 \\
(39.2 \%)\end{array}$ & $\begin{array}{c}6 \\
(6.2 \%)\end{array}$ \\
\hline $\begin{array}{l}\text { 15. Mayumi's case helped } \\
\text { me to understand the } \\
\text { importance of } \\
\text { a multidisciplinary } \\
\text { approach in child and } \\
\text { adolescent psychiatry. }\end{array}$ & $\begin{array}{c}15 \\
(65.2 \%)\end{array}$ & $\begin{array}{c}7 \\
(30.4 \%)\end{array}$ & $\begin{array}{c}1 \\
(4.4 \%)\end{array}$ & $\begin{array}{c}43 \\
(58.1 \%)\end{array}$ & $\begin{array}{c}26 \\
(35.1 \%)\end{array}$ & $\begin{array}{c}5 \\
(6.8 \%)\end{array}$ & $\begin{array}{c}58 \\
(59.8 \%)\end{array}$ & $\begin{array}{c}33 \\
(34 \%)\end{array}$ & $\begin{array}{c}6 \\
(6.2 \%)\end{array}$ \\
\hline
\end{tabular}

Note: $*(n=97$ after disregarding students who did not identify their gender/age).

Table 5 Students' Opinion of PBL and CAP

\begin{tabular}{|l|l|}
\hline Question & Correlation Coefficient* \\
\hline $\begin{array}{l}\text { Q6 PBL enhanced my understanding about CAP. } \\
\text { Q7 PBL increased my interest in CAP. }\end{array}$ & 0.7443 \\
\hline $\begin{array}{l}\text { Q1 PBL helped me develop skills in solving clinical problems. } \\
\text { Q2 PBL is a good way of learning the content of the course. }\end{array}$ & 0.7349 \\
\hline
\end{tabular}

Note: *Only strong correlation between the variables is shown (complete data are available in the Supplementary File accompanying this article).

0.7349). Students who disagreed that PBL helped them to develop their communication skills nevertheless tended to agree that Mayumi's case was well written and understandable (Table 6) $(\mathrm{R}=-0.08, \mathrm{p}<0.05)$. Supplementary Table 1 on Pearson's correlation coefficients can be found at the end of this paper.

\section{Discussion}

To our knowledge, this is the first study to investigate PBL in the field of CAP in Japan. The students' overall impressions of PBL and CAP and of specific case scenarios were generally positive, indicating a high level of satisfaction. The majority of students agreed that PBL contributed to their clinical problemsolving skills and increased their interest in CAP. More specifically, by studying the case scenario of Mayumi, students were engaged in the multidisciplinary approach of CAP.
In terms of their general impressions of PBL, a large majority of students $(82.47 \%)$ thought that PBL would help them to solve clinical problems. We hypothesized that a similar proportion of students would think that PBL was a more effective way of learning than traditional lectures, but in fact only $65.98 \%$ thought so. It seemed that more male students $(70.27 \%)$ than female students (52.17\%) thought that PBL was a more effective way of learning because they enjoyed interactive or clinically oriented learning, but this question needs additional study, as alternative explanations should be explored considering possible gender biases towards teaching styles and methods. A study from Saga Medical School, Japan investigated how a PBL approach affected the performance of its students, compared with traditional curricula. ${ }^{12}$ Students taking part in PBL tutorials were 
Table 6 Students' Impressions of Communication Skills and PBL

\begin{tabular}{|l|l|}
\hline Question & Correlation Coefficient* \\
\hline Q4 PBL helped to develop my communication skills. & -0.08 \\
Q12 Mayumi's case was well written and understandable. & \\
\hline
\end{tabular}

Note: *Only negative correlation between the variables is shown (complete data are available in the Supplementary File accompanying this article).

encouraged and motivated to spend more time studying. A similar study was published on a PBL approach at King Faisal University, Saudi Arabia and its effect on students' motivation and thinking on learning and their learning style, learning skills, and difficulties and achievements. ${ }^{13}$ Although in the current study the students' performance was not observed as an outcome of their PBL experience, this may be something to consider in future studies.

More than half of the students agreed that introducing PBL to CAP studies enhanced their understanding (53.61\%) and increased their interest in CAP (55.67\%), but fewer than half agreed that the duration of the PBL sessions was sufficient (47.42\%). Since the PBL curriculum at NU involves two sessions a week over a period of 10 months, only two case scenario sessions (90 minutes each) were provided to examine Mayumi's case; allocating more time to the case may resolve this issue. However, there are challenges to more schools and faculties in Japanese medical schools providing PBL classes, because of the high burden this approach places on them. ${ }^{10,12}$ A similar study in Ireland in 2012 showed that studying CAP for four days exclusively during a two-month period had positive impacts on fourth-year medical students. ${ }^{14}$

The responses to specific questions about Mayumi's case had positive outcomes in terms of describing adolescent depression, but fewer than half of the students (42.3\%) agreed that Mayumi's case had an interesting clinical trigger.

Of note is the fact that Mayumi's case was the only case scenario written in English, which may have caused difficulties for students and thus distracted attention from the important takeaways from the PBL sessions. A study from 2013 indicated that communication and interaction are two critical aspects of understanding PBL in CAP, and thus those whose native language was not English may have experienced substantial barriers to learning. ${ }^{5}$ Further studies should evaluate more comprehensively students' views of PBL in CAP in different languages and in different cultural scenarios.

Certain limitations, such as gender balance among students (Table 1), should be considered in interpreting these findings and to obtain more conclusive results in future studies. This is especially true because more male students (70.27\%) than female students (52.17\%) thought that PBL was a more effective way of learning. The study used self-reported questionnaires, which are subject to inherent bias, although such questionnaires are widely accepted in studies on PBL. ${ }^{15}$

The results of the study revealed overall a good impression of PBL and CAP and of the specific case scenarios presented. The PBL method increased satisfaction levels for clinical problem-solving ability for most of the students, which increased their interest in CAP. Students were engaged in the multidisciplinary approach to CAP by adapting specific case scenarios. Since there is a shortage of CAP specialists in Japan, exposing medical students to clinically interesting and engaging PBL in CAP scenarios may, in the long run, be beneficial in terms of increasing the number of CAP specialists. We hope that future studies may pave the way for PBL in CAP scenarios that are structured to spark academic curiosity and professional interest among medical students.

\section{Data Sharing Statement}

The datasets used and/or analyzed during the current study are available from the corresponding author on reasonable request.

\section{Ethics Approval and Consent to Participate}

All procedures performed in the study involving human participants were in accordance with the ethical standards of the institutional and/or national research committee and with the 1964 Helsinki Declaration and its later amendments or comparable ethical standards. This study was non-interventional (survey), and at the time it was conducted ethical approval by specialized committee was not required, as confirmed with representatives of the ethical committee at Nagoya University. Details of the study were explained to participants beforehand, and signed consent was obtained from all participants. 


\section{Consent for Publication}

All authors have read and approved the manuscript. The views expressed in the submitted article are our own and are not an official position of the institutions involved.

\section{Acknowledgments}

The authors would like to acknowledge the students of the School of Medicine at Nagoya University who participated in the study. Junko Iwatsuki and Takeshi Kondo are cofirst authors for this study. Tetsuya Yagi and Norbert Skokauskas are co-last authors for this study.

\section{Funding}

The TroNA Partnership for students and staff mobility and internationalization of child mental health studies is an UTFORSK project.

\section{Disclosure}

Dr Noriyuki Takahashi reports grants, personal fees from Novartis Japan, outside the submitted work. The authors declare that they have no other competing interests.

\section{References}

1. Cabinet Office, Japan. Annual report on the ageing society (Summary) FY 2019. Edited by Cabinet Office, Japan; 2019.

2. Yamashita J, Soma N. The double responsibilities of care in Japan: emerging new social risks for women providing both childcare and care for the elderly. Comp Dev Policy Asia. 2016;17:95-111.

3. Tateno M, Inagaki T, Saito T, Guerrero ARS, Skokauskas N. Current challenges and future opportunities for child and adolescent psychiatry in Japan. Psychiat Invest. 2017;14(5):525-531. doi:10.4306/ pi.2017.14.5.525
4. Sakano M, Snowden N. Paving the way for the future of child and adolescent mental health in Japan. London J Prim Care. 2018;10 (4):123-125. doi:10.1080/17571472.2018.1483002

5. Skokauskas N, Doody B, Gallagher L, et al. Problem-based learning in child and adolescent psychiatry at Trinity College, Dublin, Ireland. Acad Psychiatr. 2012;36(4):335-339. doi:10.1176/appi.ap.10120165

6. Spector JM. Handbook of Research on Educational Communications and Technology. 3rd ed. New York: Lawrence Erlbaum Associates; 2008.

7. Group TPR; Newman M. A Pilot Systematic Review and Metaanalysis on the Effectiveness of Problem-based Learning. Newcastle, UK: Learning and Teaching Subject Network for Medicine, Dentistry and Veterinary Medicine; 2003.

8. Hmelo-Silver CE. Problem-based learning: What and how do students learn? Educ Psychol Rev. 2004;16(3):235-266. doi:10.1023/B: EDPR.0000034022.16470.f3

9. Kozu T. Medical education in Japan. Acad Med. 2006;81 (12):1069-1075. doi:10.1097/01.ACM.0000246682.45610.dd

10. Onishi H, Yoshida I. Rapid change in Japanese medical education. Med Teach. 2004;26(5):403-408. doi:10.1080/ 01421590412331270492

11. Academic Ranking of World Universities; 2019. Available from: www.shanghairanking.com/rankings/arwu/2019 http://www.shang hairanking.com/rankings/arwu/2019. Accessed November 11, 2021.

12. Oda Y, Koizumi S. Status of medical education reform at Saga Medical School 5 years after introducing PBL. Kaohsiung $J$ Med Sci. 2008;23(3):S46-S53. doi:10.1016/S1607-551X(08)70094-9

13. Almulla MA. The efficacy of employing Problem-Based Learning (PBL) approach as a method of facilitating students' achievement. IEEE Access. 2019;7:146480-146494. doi:10.1109/ ACCESS.2019.2945811

14. Skokauskas N, Gallagher L, Frodl T, Gill M. Assessing problem based learning in child and adolescent psychiatry at the Trinity College Dublin, Ireland. Oman Med J. 2012;27(2):168-169. doi:10.5001/omj.2012.35

15. Guo PY, Saab N, Post LS, Admiraal W. A review of project-based learning in higher education: student outcomes and measures. Int J Educ Res. 2020;102:101586. doi:10.1016/j.ijer.2020.101586

\section{Publish your work in this journal}

Advances in Medical Education and Practice is an international, peerreviewed, open access journal that aims to present and publish research on Medical Education covering medical, dental, nursing and allied health care professional education. The journal covers undergraduate education, postgraduate training and continuing medical education including emerging trends and innovative models linking education, research, and health care services. The manuscript management system is completely online and includes a very quick and fair peer-review system. Visit http://www.dovepress.com/testimonials.php to read real quotes from published authors. 